reimbursement of such medicine to COPD patients introduced in Norway in 2006. Most recently, combined ICS/LABA inhalers are once again reimbursed for COPD in Norway, but only when the $\mathrm{FEV}_{1} \%$ predicted is $<60 \%$.

\section{Conflicts of interest}

None.

\section{Funding}

The project has received financial support from SINTEF Helse.

\section{References}

1. Arif AA, Delclos GL, Lee ES, Tortolero SR, Whitehead LW. Prevalence and risk factors of asthma and wheezing among US adults: an analysis of the NHANES III data. Eur Respir J 2003;21(5):827-33. http://dx.doi.org/10.1183/ 09031936.03.00054103a

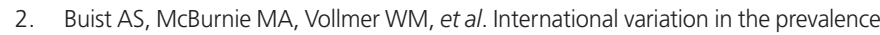
of COPD (the BOLD Study): a population-based prevalence study. Lancet
2007;370(9589):741-50. http://dx.doi.org/10.1016/S0140-6736(07) 61377-4

3. Nacul L, Soljak M, Samarasundera E, et al. COPD in England: a comparison of expected, model-based prevalence and observed prevalence from general practice data. J Public Health (Oxf) 2011;33(1):108-16. http://dx.doi.org/10.1093/pubmed/fdq031

4. Karlstad O, Nafstad P, Tverdal A, Skurtveit S, Furu K. Prevalence, incidence and persistence of anti-asthma medication use in 2- to 29-year-olds: a nationwide prescription study. Eur J Clin Pharmacol 2010;66:399-406. http://dx.doi.org/10.1007/s00228-009-0749-x

5. McGowan B, Bennett K, Barry M, Owens M, O'Connor M. An analysis of the utilisation and expenditure of medicines dispensed for the management of severe asthma. Ir Med J 2009;102(3):73-6.

6. Haugan T, Bakken IJ, Storrø O, Øien T, Langhammer A. [Utilization of diagnostic tol and heakth care services for obstructive lung disease. Tidsskr Nor Laegeforen 2008;128:2431-4 (Norwegian).

7. Enright P, White P. Detecting mild COPD: don't waste resources. Prim Care Respir J 2011;20(1):6-8. http://dx.doi.org/10.4104/pcrj.2011.00004

\title{
GPs' role in reducing the risk of bronchospasm in asthma patients undergoing general anaesthesia and/or intravascular administration of radiographic contrast media
}

\author{
Gennaro Liccardi ${ }^{a}$ Antonio Infantinob ${ }^{b}$ Pierluigi Paggiaroc, Leonardo Maria Fabbri ${ }^{d}$, \\ Antonello Salzillo ${ }^{a}$, Ruben Infantino ${ }^{e}$ * Gennaro D'Amato ${ }^{*}$ \\ a Department of Chest Diseases, Division of Pneumology and Allergology High Speciality "A. Cardarelli" Hospital, Naples, Italy \\ b Italian Academy of Family Physicians Bari, Italy \\ c Department of Cardio-Thoracic and Vascular Diseases, University of Pisa, Italy \\ d Department of Respiratory Medicine, University of Modena and Reggio Emilia, Modena, Italy \\ e Department of Medical Methodologies and Medical-Surgical Technologies, Respiratory Diseases Unit, University of Bari, Italy
}

\begin{abstract}
*Correspondence: Professor Gennaro D’Amato, Department of Chest Diseases, Division of Pneumology and Allergology, High Speciality "A. Cardarelli" Hospital, Via Rione Sirignano n. 10, 80122, Naples, Italy Tel: +39081 7473335-4-3 Fax: + 390817473331

E-mail: gdamato@qubisoft.it

Submitted 20th March 2011; accepted 22nd March 2011 ; online 25th May 2011

(C) 2011 Primary Care Respiratory Society UK. All rights reserved http://dx.doi.org/10.4104/pcrj.2011.00044
\end{abstract}

\section{Dear Sirs,}

Asthma is recognised as a highly prevalent health problem in the developed and developing world. Its inadequate control is the main reason for the increased risk of bronchospasm in children or adults undergoing surgical intervention under general anaesthesia (surgery
+ GA) or intravascular administration of radiographic contrast media (RCM) for diagnostic purposes..$^{1,2}$ Severe perioperative bronchospasm has been reported in $0.17-4.2 \%$ of all GA procedures carried out in patients with asthma, ${ }^{3}$ and severe bronchospasm has been reported in $0.18-4 \%$ of procedures using RCM. Bronchospasm in asthma patients may lead to several peri- and/or post-operative and RCMrelated complications (see Table 1). However, the international GINA Guidelines ${ }^{4}$ contain only a few sentences on the risk of surgery + GA for asthma patients, and there is no mention of the risk of intravascular RCM administration.

Although there is little if any literature on the relationship between the degree of asthma control and the risk of intraoperative/intra-RCM infusion bronchospasm, good clinical practice suggests that optimal control of asthma symptoms in 'real life' is an important prerequisite for safer surgery (either elective or

Table 1. Possible consequences of bronchospasm in asthma patients undergoing GA and / or administration of RCM

\begin{tabular}{ll|l} 
Surgery with GA & & Use of RCM \\
\hline Perioperative & Postoperative & $\bullet$ Hypoexmia \\
- Hypoxemia & - Mucus plugging and segmental atelectasis & $\bullet$ Increase of airway resistance \\
- Increase of airway resistance / alveolar & - Wheezing & Necessity of discontinuing the procedure \\
hypoventilation & - Pneumonia & - Alteration of RCM diffusion from vascular / \\
- Prolonged intubation & - Aspiration of biologic materials $\left(^{*}\right)$ & ventilatory alteration induced by hypoxemia \\
related vasoconstriction.
\end{tabular}


Figure 1. Role of the general practitioner and other specialists in the management of asthma
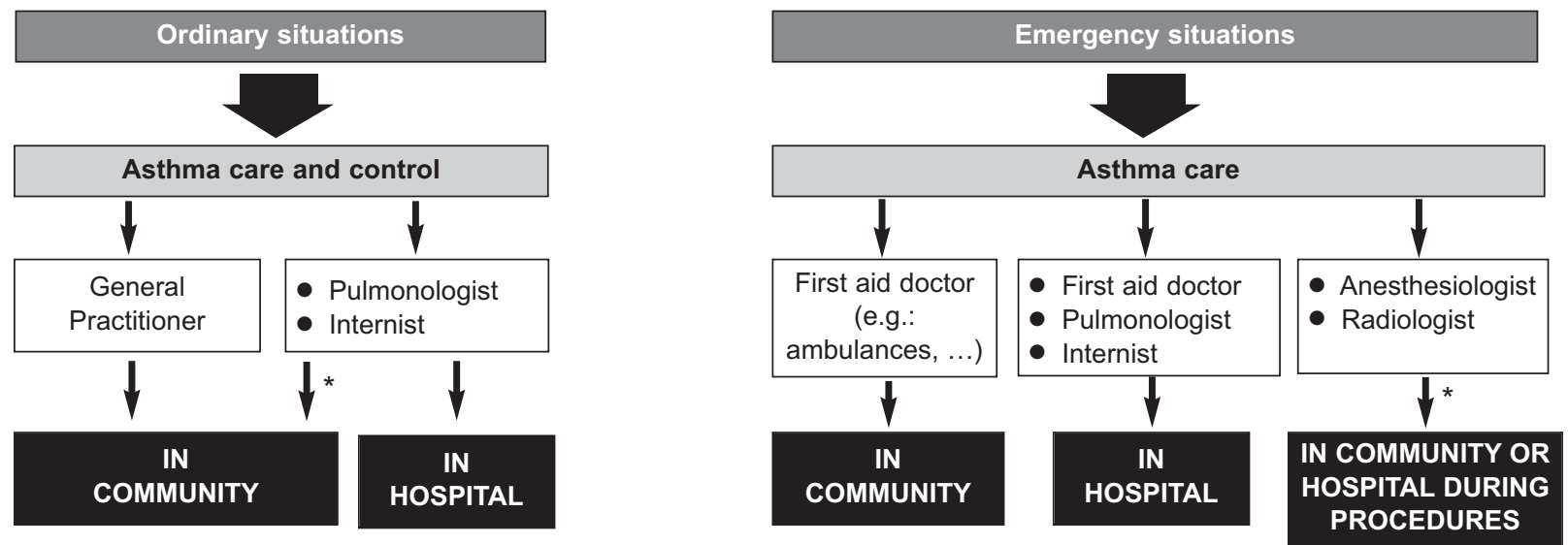

* in those national health services - like Italy - that have these specialists working outside of hospitals

emergency) requiring GA and/or RCM administration. The few available data emphasise the role of optimal clinical, functional, and therapeutic management in order to obtain best possible control of airway inflammation and clinical symptoms prior to these procedures. ${ }^{1.5,6}$

Different doctors (the general practitioner (GP) as well as other specialists) are involved in asthma care and asthma control (see Figure 1). The management of bronchospasm occurring during surgery + GA as well as during RCM administration is usually carried out by anaesthesiologists and radiologists. In emergency situations, patients with uncontrolled asthma display the highest risk of bronchospasm because no assessment of asthma control can be performed prior to the procedure and sometimes only short-term premedication can be administered.' In "high speciality" hospitals, if surgery + GA and/or RCM use is planned, a preliminary assessment of asthma patients can be performed by pulmonologists or by respiratory-trained physicians, and if necessary adequate therapy initiated to reduce the risk of obstructive airway complications. ${ }^{8}$ The problem arises for those asthma patients undergoing surgery + GA in hospitals without pulmonologists, or when procedures requiring administration of intravascular RCM must be carried out in outpatient departments; in this latter situation, there is usually no preventative specialist opinion available.

It is widely acknowledged that disease control is inadequate in a large number of asthma patients for a number of reasons, although 'disease control' is the most important goal for all physicians involved in asthma care (see Figure 1). We believe that the problem faced by asthma patients when they are about to undergo planned surgery + GA or intravascular administration of RCM should be considered in the context of their overall 'real life' management - and that consequently the role of the GP is of paramount importance. Therefore, we believe that it is the responsibility of the GP to check beforehand that the degree of asthma control prior to these procedures is optimal. If the GP knows that his or her asthma patient is about to undergo surgery + GA or intravascular RCM administration, they should check the patient's asthma control by administering an asthma questionnaire or by performing office spirometry (if equipped). In the case of poor disease control, treatment should be modified and the patient reviewed again. The GP might also require a specialist or secondary care consultation for the patient prior to surgery + GA or RCM administration. Thus, optimally controlled asthma patients will be able to have their procedures performed without additional pre-treatment if the preoperative respiratory assessment (carried out in hospital) confirms good disease control.

In addition, the GP should also evaluate other risk factors related to concomitant allergic diseases such as drug and latex allergy. In these patients it could be useful to administer antihistamines to prevent or at least reduce the magnitude of potential systemic reactions. ${ }^{9}$

GPs should be aware of their central role in managing asthma patients in 'real life'. This entails increasing efforts to obtain optimal asthma control by using an adequate therapeutic regimen, effective measures to reduce exposure to disease triggers, educational support, specialist referrals, and the use of validated questionnaires such as the Asthma Control Questionnaire (ACQ) or the Asthma Control Test (ACT) - which can be administered by telephone. ${ }^{10}$

Prospective large studies should be planned to study the risk of bronchospasm for asthma patients undergoing surgery + GA or $\mathrm{RCM}$ administration, and the cost/benefit ratio of obtaining optimal disease control prior to the procedure, including prescribing of appropriate therapy and preliminary checks by GPs of patients' asthma control status. This would likely lead to improved GINA Guideline implementation and a reduction in the risk of bronchospasm in asthma patients undergoing surgery + GA or RCM administration.

\section{Conflicts of interest}

All authors declare no conflict of interest in relation to this article.

\section{References}

1. Tirumalasetty J, Grammer LC. Asthma, surgery and general anaesthesia: a review. J Asthma 2006;43(4):251-4. http://dx.doi.org/10.1080/02770900600643162

2. Al-alami AA, Zestos MM, Baraka AS. Pediatric laryngospasm: prevention and treatment. Curr Opin Anaesthesiol 2009;22(3):388-95. http://dx.doi.org/ 10.1097/ACO.0b013e32832972f3 
3. Bremerich DH, Anesthesia in bronchial asthma. Anasthesiol Intensivmed Notfallmed Schmerzther 2000;35(9):545-58. http://dx.doi.org/10.1055/s-2000-7091

4. Global Initiative for Asthma. Global Strategy for asthma Management and Prevention. Updated 2009 (www. ginasthma.com)

5. Smetana GW. Preoperative pulmonary evaluation. N Engl J Med 1999;340: 93744. http://dx.doi.org/10.1056/NEJM199903253401207

6. Liccardi G, Salzillo A, Piccolo A, De Napoli I, D'Amato G. The risk of bronchospasm in asthmatics undergoing general anaesthesia and/or intravascular administration of radiographic contrast media. Physiopathology and clinical/functional evaluation. Eur Ann Allergy Clin Immunol 2010;43:167-73

7. Liccardi G, Salzillo A, De Blasio F, D'Amato G. Control of asthma for reducing the risk of bronchospasm in asthmatics undergoing general anestesia and/or intravascular administration of radiographic contrast media. Curr Med Res Opin
2009;25(7):1621-30. http://dx.doi.org/10.1185/03007990903010474

8. Liccardi G, Salzillo A, D'Amato G. II rischio di broncospasmo nei pazienti asmatici da sottoporre ad anestesia generale o a somministrazione endovascolare di mezzi di contrasto diagnostici. Aspetti fisiopatologici, clinici e valutativi. Rass Patol App Respir 2007;22(6):407-14.

9. Liccardi G, Lobefalo G, Di Florio E, et al. on behalf of C.H.R.A.i.A.P (Cardarelli Hospital Radio Contrast Media and Anesthetic induced Anaphylaxis Prevention) Working Group. Strategies for prevention of asthmatic, anaphylactic and anaphylactoid reactions during the administration of anaesthetics and / or contrast media (CM). J Investig Allergol Clin Immunol 2008;18:1-11.

10. Nathan RA, Sorkness CA, Kosinski M, et al. Development of the asthma control test: a survey for assessing asthma control. J Allergy Clin Immunol 2004;113(1):5965. http://dx.doi.org/10.1016/j.jaci.2003.09.008

\section{Available online at http://www.thepcrj.org}

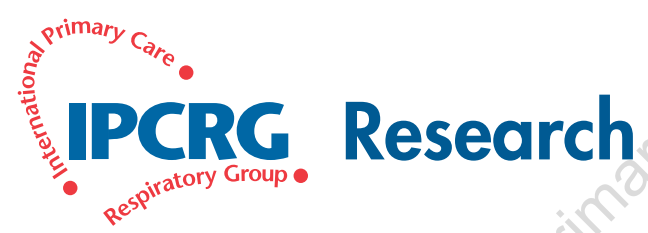

\section{6th World Conference, Edinburgh}

Abstracts are now accepted for this meeting http://www.ipcrg-pcrs201 2.com/abstracts/index.php

For inspiration, have a look at the abstracts from our recent scientific meeting in Amsterdam showcasing new pragmatic respiratory research in primary care from around the world, available to view in the extended online edition of the June 2011 issue of the $P C R /$ available at www.thepcri.org

\section{Primary care respiratory networks}

To increase the research capability of primary care around the world, and to assist in communication on research topics between colleagues, we are setting up regional networks, each led by one of our Research sub-committee. If you wish to get in touch with colleagues in your region, as a prelude to developing a multi-national project, or simply to share and compare existing data, please contact the relevant lead at https://www.theipcrg.org/about/regional_leads.php

\section{Respiratory At@Glance}

Subscribe to the IPCRG's free monthly one page Respiratory At@Glance that features summaries of key papers that meet our criteria: relevant to primary care and published within the last 6 months.

\section{Register at http://www.theipcrg.org/mail/index.php}

